Pediat. Res. 1: 341-353 (1967)

Lactic acid intestinal villi

intestine steatorrhea

\title{
Prolonged Infusion of the Small Intestine of the Rat - Effect of Dilute Solutions of Lactic Acid on Fat Absorption and Mucosal Morphology
}

\author{
J.R. HAMILTON ${ }^{[33]}$ \\ Department of Pediatrics, University of Toronto, \\ and the Hospital for Sick Children, Toronto, Canada
}

\begin{abstract}
Extract
A satisfactory technique for the continual infusion of solutions into the intestinal tract of the small animal was developed. Using this technique, dilute solutions of lactic acid were infused into the rat and their effect on fat absorption and mucosal structure assessed. Thirty-five rats were studied in five groups, infused with either ion-free water or lactic acid $(2.0 \mathrm{~g} / 100 \mathrm{ml}, 2.5 \mathrm{~g} / 100 \mathrm{ml}, 3.0 \mathrm{~g} / 100 \mathrm{ml}$, $3.5 \mathrm{~g} / 100 \mathrm{ml}$ ) for 10 days. Fecal fat excretion measured as a percentage of ingested fat was increased significantly in rats infused with acid in a concentration of $3.0 \mathrm{~g} / 100 \mathrm{ml}(7.2 \pm 2.1)$ and $2.5 \mathrm{~g} / 100 \mathrm{ml}$ $(6.5 \pm 2.1)$ compared to the water-infused group $(2.9 \pm 1.9)$ or those infused with lactic acid $2.0 \mathrm{~g} / 100$ $\mathrm{ml}(2.2 \pm 0.9)$. Six rats infused with lactic acid $3.5 \mathrm{~g} / 100 \mathrm{ml}$ died within 72 hours of a perforated intestine and the two remaining ones were killed prematurely for histological study.

Histological abnormalities were confined to the small intestine. Mucosal structure was normal in both the water-infused group and those receiving lactic acid $2.0 \mathrm{~g} / 100 \mathrm{ml}$. Shortening of villi occurred at the site of infusion in both the groups infused with lactic acid $2.5 \mathrm{~g} / 100 \mathrm{ml}$ and $3.0 \mathrm{~g} / 100 \mathrm{ml}$. Fusiform processes of epithelial cells were observed extending on narrow pedicles from the tips of some of the shortened villi. Gross derangement of villous structure was observed in two rats killed after 48 hours on the most concentrated acid $(3.5 \mathrm{~g} / 100 \mathrm{ml})$.

It is probable that the abnormalities in fat absorption and mucosal structure were a direct effect of the infusion with lactic acid. The mechanism behind the development of steatorrhea can only be the subject of speculation. The histological observations suggest that the lesions produced in the mucosa were associated with disordered turnover of the surface epithelial cells.
\end{abstract}

\section{Speculation}

A new technique for the continual long-term infusion of the small intestine of small animals may have considerable application to the study of normal and abnormal intestinal function and structure in the future. The observations of disordered fat absorption and mucosal lesions in response to the infusion of an organic acid into the intestinal lumen may be relevant to the study of the pathogenesis of certain malabsorptive states. 


\section{Introduction}

This report deals with a study of the effect of prolonged infusion of lactic acid into the proximal portion of the small intestine of the rat. A new technique for the continual infusion of solutions into the intestinal tract of the small animal was developed. Using this technique, dilute solutions of lactic acid were infused into the rat and their effect on fat absorption and mucosal structure assessed.

Lactic acid is an organic acid that may be produced within the lumen of the intestinal tract by the bacterial fermentation of carbohydrate [17,25]. Although some lactic acid is formed in the intestinal mucosal epithelium during the absorption of glucose and fructose, apparently little of this endogenous acid is released into the bowel lumen [27]. A relatively strong acid, its accidental ingestion in quantity by children has led to fatal gangrenous gastritis and enterocolitis [7,28]. Its irritant action on the intestinal mucosa of the rabbit also has been demonstrated in acute experiments [28].

\section{Materials and Methods}

Male Wistar rats (initial weights $180 \mathrm{~g}$ to $236 \mathrm{~g}$ ) were studied.

They were fed a semipurified, nutritionally complete diet, containing $15 \mathrm{~g}$ of fat (corn oil $10 \mathrm{~g}$, lard $5 \mathrm{~g}$ ) per $100 \mathrm{~g}$ of diet.

The diet was offered ad libitum throughout the infusion period beginning at least three days prior to the onset of the infusion. Total daily intake and thus daily fat intake were calculated by weighing the food offered each day and subtracting from it the weight of the food left or scattered. Reagent grade Lactic Acid ${ }^{1}$ was made up to the desired dilution with ion-free water for each infusion study. The $\mathrm{pH}$ and osmolarity of the solutions used are shown in table I. Tail cups described by BARNes [1] were used on all animals for fecal collections. Complete collections could be obtained and coprophagy prevented by this method.

Feces for each three- or four-day period were made up to $250 \mathrm{ml}$ volume with tap water, homogenized, and the assay for total fat carried out on $10 \mathrm{ml}$ aliquots using the method of VAN DE KAMER et al. [24]. Excretion was expressed as a percentage of ingested fat. Tissue taken for histological examination was fixed first in Bouin's solution for 4 hours and subsequently in $70 \%$ ethanol. All paraffin sections were stained with hematoxylin and eosin. In addition, PAS and reticulin stains [9] were used on selected sections. Measurements were made using a standard micrometer on multiple sections selecting only those villi that were cut precisely in the longitudinal axis.

${ }^{1}$ J.R.Baker Company, Phillipsburg, N.J. (USA).
Table I. The concentrations of lactic acid used in experiments

\begin{tabular}{llllll}
\hline $\begin{array}{l}\text { Group Number Infusate } \\
\text { of rats }\end{array}$ & $\begin{array}{l}\text { Concen- } \\
\text { tration } \\
(\mathrm{g} / 100 \mathrm{ml})\end{array}$ & $\begin{array}{l}\mathrm{pH} \\
\text { ity } \\
\text { mOsmosmolar- }\end{array}$ \\
\hline 1 & 7 & water & - & - & - \\
2 & 6 & lactic acid & 2.0 & 2.6 & 186 \\
3 & 6 & lactic acid & 2.5 & 2.4 & 240 \\
4 & 8 & lactic acid & 3.0 & 2.2 & 284 \\
5 & 8 & lactic acid & 3.5 & 2.1 & 333 \\
\hline
\end{tabular}

The technique for the implantation of a cannula in the small intestine was as follows. Under ether anesthesia after an overnight fast, a ventral midline incision was made in the abdominal wall of the rat. Through a stab incision in the gastric antrum, the distal end of a length of fine vinyl tubing ${ }^{2}$ was inserted into the stomach, through the pylorus along the small intestine for a distance of approximately $15 \mathrm{~cm}$. The cannula was secured by a purse string suture fixing the tube at the antral wall. The proximal end of the tube was brought out through the anterior peritoneal wall and abdominal muscle. It was passed through a dissected subcutaneous tunnel to the back and brought out through an interscapular skin incision where it was incorporated into a stainless steel mesh harness, similar to that described by Holrzman and VISEx [12]. The cannula, in effect a jejunal fistula, was occluded and the rat returned to its cage. Aseptic techniques were observed. The cannulas were placed in antiseptic solution ${ }^{3}$ for 24 hours before use and rinsed with sterile saline just prior to surgery.

The apparatus for the infusion of small intestine was adapted from the gastric infusion apparatus described by Holtzman and Visek [12]. The rat was harnessed to a length of flexible cable, the proximal end of which was fixed to a specially designed cage lid by means of a water-tight swivel. Through the swivel by means of tubing passed through the cable and connected to the cannula in the rat, solutions could be delivered to the animal at any desired rate for a prolonged period while the animal moved freely and fed normally in its cage.

A detailed cross-sectional drawing of the swivel is shown in figure 1. Using four such devices, four rats could be infused simultaneously. A quadruple syringe infusion pump was used to deliver solutions at a constant rate from four $30 \mathrm{ml}$ syringes ${ }^{4}$.

2 Portex (PT-2) O.D. $1.50 \mathrm{~mm}$, Portland Plastics, Kent (England).

3 Zephiran (aqueous solution 1:20,000), Winthrop Laboratories, Aurora (Canada).

${ }^{4}$ Model 600-930, Harvard Apparatus Co., Dover, Mass. (USA). 


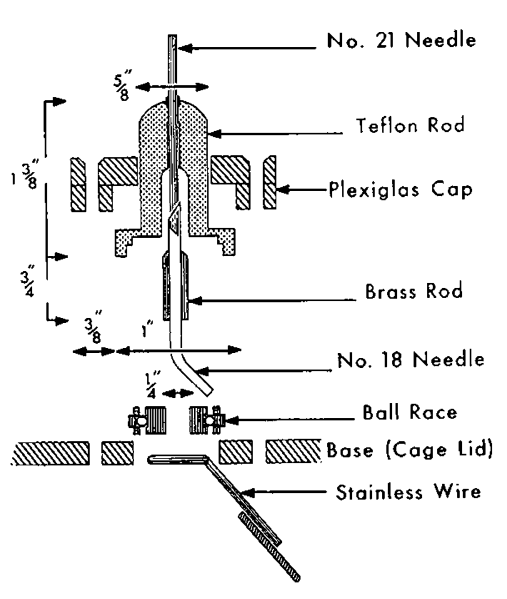

Fig. 1. Swivel for infusion apparatus. - a) Base. A sheet of plexiglas $10^{\prime \prime} \times 12^{\prime \prime} \times 3 / 16^{\prime \prime}$ served as the base for the swivel in addition to being the top of the cage. The center of the base was drilled to take a ball race. Presumably the dimensions of the base can be adjusted to fit any standard single rat cage. b) Ball race. A standard $3 / 4 "$ ball race was used. A piece of $1 / 16^{\prime \prime}$ stainless steel wire was shaped to form a circle, approximately $1 / 2$ " in diameter with ends projecting for $1^{\prime \prime}$ at an angle of $45^{\circ}$. c) Brass rod. A brass rod $3 / 4^{\prime \prime} \times 1 / 4^{\prime \prime}$ was drilled to take the shaft of a No. 18 needle, $1-3 / 4^{\prime \prime}$ in length. The upper end was rounded and the lower soldered into the base of the bearing core. The needle was inserted through the brass rod with $1 / 2$ " projecting from the domed end, soldered in position and the lower end bent to a $45^{\circ}$ angle as shown. d) Teflon rod. The upper end was recessed as shown with a shoulder to support the outer case of the bearing. A $1 / 4^{\prime \prime}$ hole was drilled to accept the brass insert, a further hole for the No. 18 needle shaft. The No. 21 needle was fixed in the teflon rod with a drop of solder placed on the needle so that it projected $1 / 2^{\prime \prime}$ from the top and approximately $1-1 / 8^{\prime \prime}$ down into the lumen of the large No. 18 needle. e) Cap. A plexiglas cap ( $1^{\prime \prime}$ in diameter) was made as shown, drilled and recessed to accept the teflon tube. Equally spaced holes were drilled so that three screws $(1 / 2-6-32)$ could be inserted around the circumference. Holes were drilled and threaded in the base at opposing locations and the entire unit then fixed to the base.f) Cable. Standard movie projector cable was soldered to the wire bracket on the bearing as described by HoLtzMAN and VISEK [12] and cut to a length that allowed the rat sufficient mobility to reach all parts of the cage. An oblong of stainless steel mesh was soldered to the lower end of the cable as described by the same authors. This oblong could then be fixed to the hitch on the back of the rat with two pieces of soft wire.
Experimental Procedure

Infusions were begun approximately seven days after implantation of the cannulas when the rats had regained their preoperative weights and had been taking the semipurified diet for at least five days.

Each rat was infused for 10 days at a rate of $43.2 \pm 1.6$ $\mathrm{ml}$ per day. Drinking water was withheld during the infusion period. The infusion rate was designed to approximate the daily water intake of a normal rat of the same weight. Stools were collected and pooled over three- or four-day periods. Each rat was weighed at the beginning and at the end of the ten-day infusion period. Food intake was recorded daily.

At the end of the infusion period, the rats were anesthetized with ether and the entire small intestine quickly removed with the distal portion of the cannula fixed in place as a reference point. Segments of intestine, $2 \mathrm{~cm}$ in length, were taken at the following levels.

a) midway, cannula tip to pylorus

b) immediately proximal to (c)

c) at the cannula tip

d) immediately distal to (c)

e) $5 \mathrm{~cm}$ distal to (d)

f) midway between (c) and the cecum

The segments, which included the entire thickness of the bowel wall, were divided longitudinally and spread on a piece of card to facilitate orientation and to prevent curling. The tissue, adherent to the card, was fixed immediately.

Blocks of liver and pancreas were also taken for histological study.

The thirty-five rats were studied in five groups as shown in table I.

The rats adjusted well to the infusion apparatus. They moved about freely and did not struggle. All survived the ten-day infusion except for eight rats in Group 5 (lactic acid $3.5 \mathrm{~g} / 100 \mathrm{ml}$ ) which developed severe diarrhea on the first day of infusion. Six of the eight died within 72 hours; the other two were killed 48 hours after the onset of the infusion. Diarrhea was noted in all rats of Group 5, in five rats of Group 4, but in none of the other animals.

\section{Food Intake and Weight Gain}

The mean daily food intake and the total ten-day weight gain of all the rats are shown in table II. The rats infused with water ate and gained weight normally. Although mean food intake did not vary significantly, there was a significant decrease in weight gain $(\mathrm{p}<0.001)$ in the rats that received lactic acid $2.5 \mathrm{~g} \%$ and $3.0 \mathrm{~g} \%$. The group infused with lactic acid $3.5 \mathrm{~g} \%$ ate virtually nothing and all lost weight. 

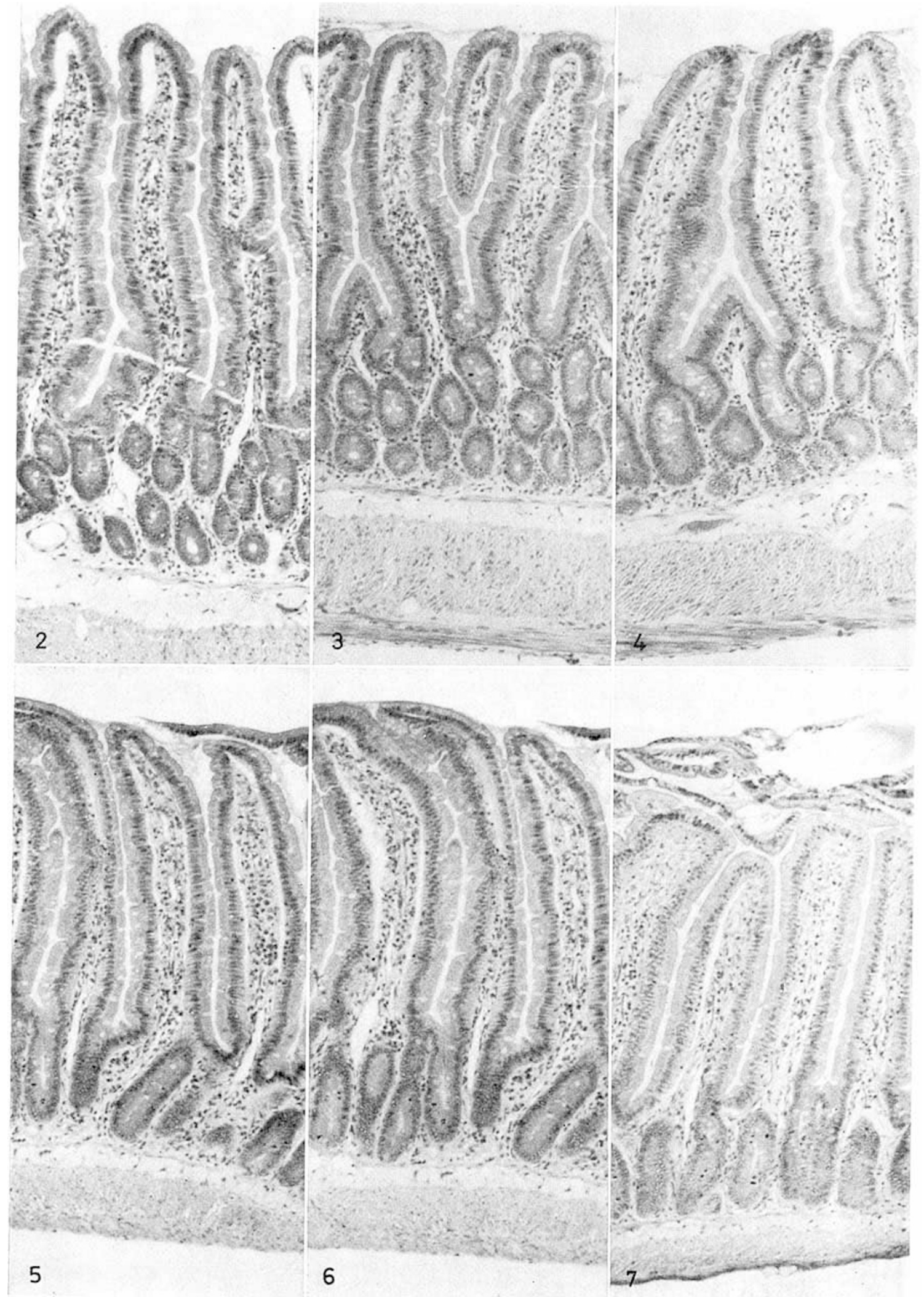

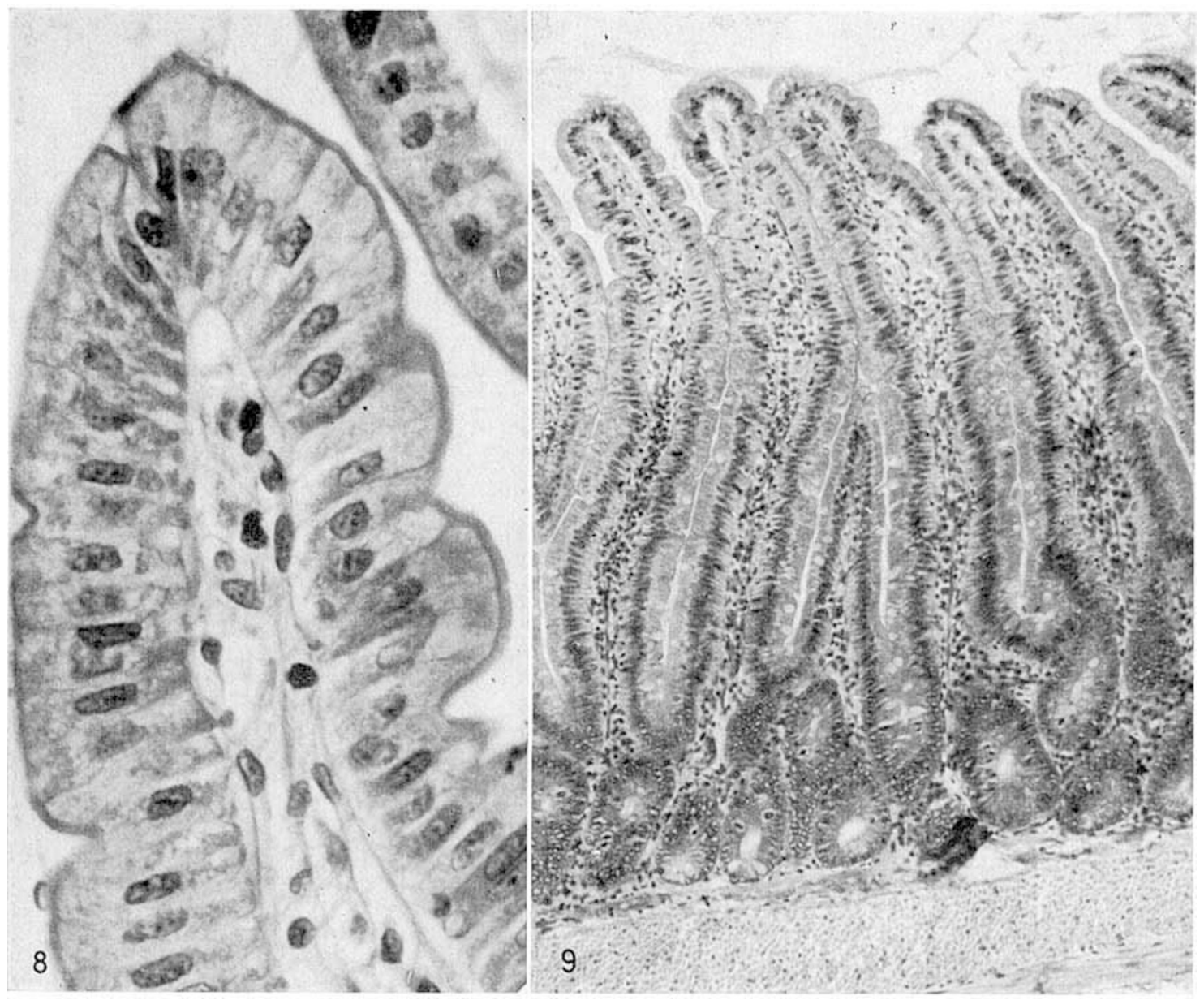

Fecal Fat Excretion

Fecal fat excretion data, listed in table II, demonstrated that those rats which were infused with higher concentrations of lactic acid $(2.5 \mathrm{~g} \%$ and $3.0 \mathrm{~g} \%)$ absorbed dietary fat less well than did those that received water or lactic acid $2.0 \mathrm{~g} \%$. Although these differences

Figs.2-7. Intestinal mucosa from a water-infused rat demonstrating normal villi with regular columnar epithelium. $\mathrm{H}$ and $\mathrm{E} ; \times 30$.

Fig. 2. Level (a) proximal to cannula tip.

Figs. 3, 4 and 5. Levels (b) (c) (d) sections from consecutive blocks at the infusion site.

Fig. 6. Level (e) $5 \mathrm{~cm}$ distal to (d).

Fig.7. Level (f) mid-ileum.

Fig.8. Water-infused rat. A villus at the level of the tip of the infusion cannula (c) with regular columnar epithelium. $\mathrm{H}$ and $\mathrm{E} ; \times 200$.

Fig.9. Rat infused with lactic acid $2.0 \mathrm{~g} \%$. Normal villous structure taken at the level of the tip of the infusion cannula (c). $\mathrm{H}$ and $\mathrm{E} ; \times 30$.

Table II. The effect of acid infusion on food intake, weight gain and fecal fat excretion

\begin{tabular}{llll}
\hline Group & Food intake & Weight gain & $\begin{array}{l}\text { Fecal fat } \\
\text { excretion } \\
\% \text { fat ingested }\end{array}$ \\
& $\begin{array}{l}\text { g/day } \\
\text { (mean } \pm \text { S.D.) }\end{array}$ & $\begin{array}{l}\text { g/10 days } \\
\text { (mean } \pm \text { S.D.) } \\
\text { (mean } \pm \text { S.D.) }\end{array}$ \\
\hline 1 & $14 \pm 5$ & $36 \pm 15$ & $2.9 \pm 1.9$ \\
2 & $15 \pm 6$ & $26 \pm 14$ & $2.2 \pm 0.9$ \\
3 & $11 \pm 5$ & $15 \pm 9$ & $6.5 \pm 2.1$ \\
4 & $10 \pm 4$ & $19 \pm 6$ & $7.2 \pm 2.1$ \\
5 & - & - & - \\
\hline
\end{tabular}

23 Pediat. Res., Vol. 1, No. 5 (1967) 


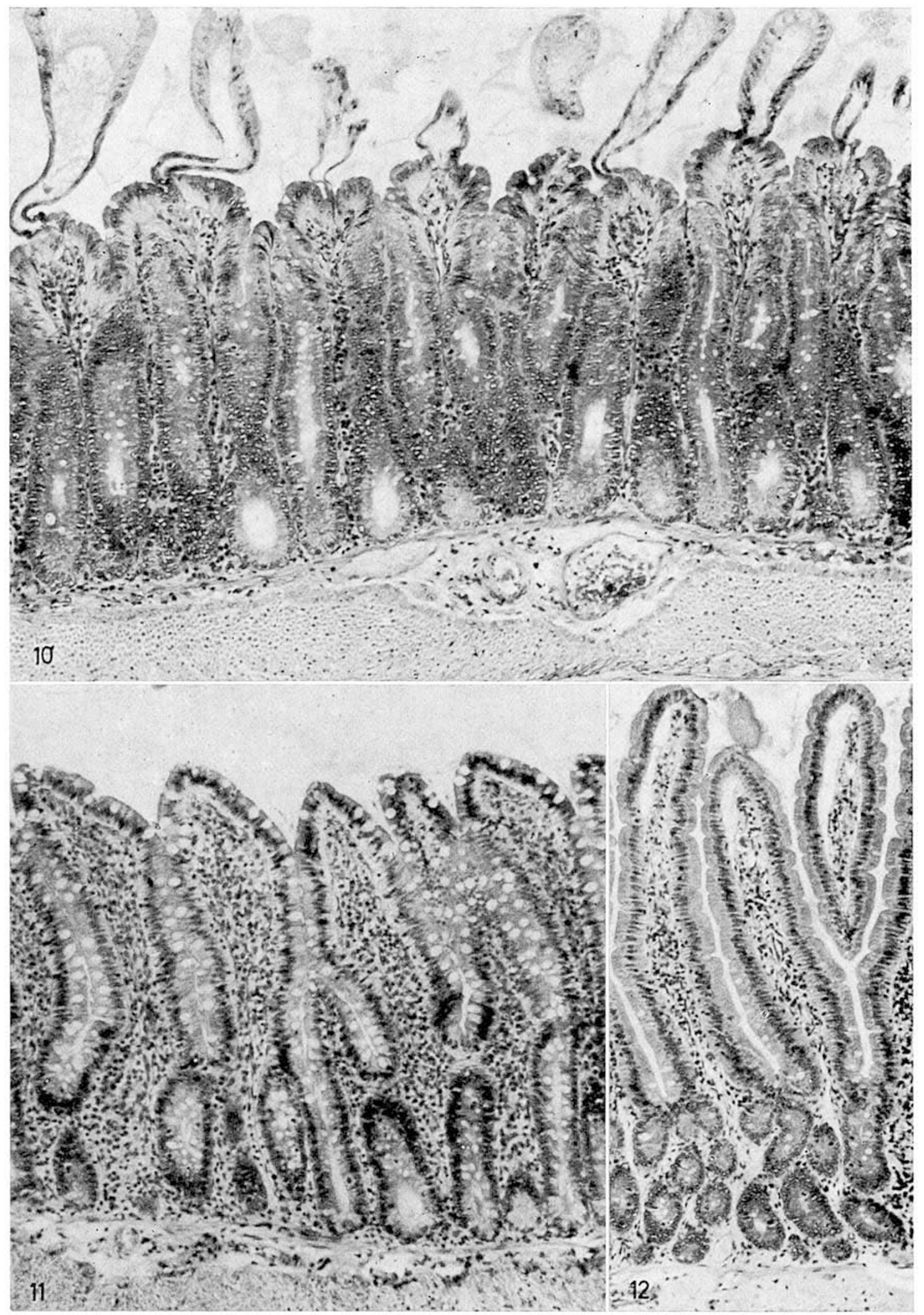


were significant $(p<0.001)$, the steatorrhea was not severe. The figures represent a mean value for the tenday period of the infusion. Although there were three consecutive collections of feces during that ten days, there was no significant difference between the consecutive values obtained for the same rat.

\section{Necropsy Findings}

Gross. Abnormalities were confined to the intestinal tract. The proximal portion of the bowel was distended and reddened in all of the rats infused with lactic acid $3.0 \mathrm{~g} \%$ and in five infused with lactic acid $2.5 \mathrm{~g} \%$. Those rats which died during the infusion of the $3.5 \mathrm{~g} \%$ solution had necrotic intestinal perforations at the site of infusion with the accumulation of fecal fluid in the peritoneal cavity. Except for the two rats in the group which were killed after two days, adequate tissue could not be obtained for histological study because of extreme autolysis.

Microscopic. Abnormalities were confined to the small intestine. Sections taken at intervals along its length from a typical rat in Group 1 (water infused) are shown in figures $2-7$. The villous structure is intact throughout the intestine, with a regular, columnar surface epithelium shown in greather detail in a high power view taken at the site of infusion (fig. 8). A section of intestine from a rat in Group 2 (fig. 9), taken at the infusion site, shows the same normal villous pattern, typical of the group infused with lactic acid 2.0 $\mathrm{g} \%$.

Figures 10 and 11 demonstrate the striking shortening of villi seen in the mucosa of rats infused with lactic acid $2.5 \mathrm{~g} \%$. In this group, abnormalities were localized to the site of infusion and normal villi were seen $5 \mathrm{~cm}$ distal to the infusion site (fig. 12). Of particular interest were the fusiform processes extending from tips of villi in three rats of the group (fig. 10). These processes occurred adjacent to the site of infusion and always at the tips of villi. Their size seemed to vary although apparent size depends to a considerable extent on the plane

Fig. 10. Rat infused with lactic acid $2.5 \mathrm{~g} \%$. Shortened villi are seen with fusiform projections from their tips. Section taken at the level of the infusion cannula (c). $\mathrm{H}$ and $\mathrm{E} ; \times 30$.

Fig. 11. Rat infused with lactic acid $2.5 \mathrm{~g} \%$. Shortened villi at level (c). Abnormality less marked than that demonstrated in figure $10 . \mathrm{H}$ and $\mathrm{E} ; \times 30$.

Fig. 12. Rat infused with lactic acid $2.5 \mathrm{~g} \%$. Normal villi approximately $5 \mathrm{~cm}$ distal to the tip of the infusion cannula. $\mathrm{H}$ and $\mathrm{E} ; \times 30$. of section. Only when they were large was there necrosis of the epithelial cells that encompassed them. Necrosis occurred at the outer margin of the larger processes where nuclear changes were seen and the cells failed to take up stain normally. The processes usually arose from a narrow pedicle of epithelial cells (fig. 13). Goblet cells were observed in these processes (figs. 14 and 15). The substance of the core of the structures was amorphous (fig. 10). It contained neither red blood cells nor inflammatory cells and failed to stain with PAS or reticulin stains (figs. 14 and 15).

Figures 16-19 demonstrate mucosal abnormalities in a rat from Group 4 (lactic acid $3.0 \mathrm{~g} \%$ ). The changes did not differ appreciably from the more advanced changes that developed in rats of Group 3, although they seemed more extensive. Abnormalities were evident in villi proximal to the infusion site (fig. 16) and extended distally beyond the infusion site as shown immediately distal (fig. 18) and $5 \mathrm{~cm}$ distal (fig. 19) to the cannula tip. These abnormalities were seen in all rats in the group and, again, the same fusiform processes were observed (fig. 17).

Further data on villous structure were derived from measurements of mucosal thickness and total villous height carried out on sections taken at the infusion site (level c) from Groups 1, 2, 3 and 4. The results shown in table III demonstrate the significant $(p<0.001)$ shortening of villi in Groups 3 and 4 . Total mucosal thickness did not alter appreciably, although there was a significant decrease in Group $4(\mathrm{p}<0.01)$ when compared with Groups 1 and 2.

Table III. The effect of acid infusion on mucosal thickness and villous length

\begin{tabular}{lll}
\hline $\begin{array}{l}\text { Group } \\
(\mu)\end{array}$ & $\begin{array}{l}\text { Mucosal thickness } \\
\text { mean } \pm \text { S.D. } \\
(\mathrm{n}=30)\end{array}$ & $\begin{array}{l}\text { Villous length } \\
(\mu) \\
\text { mean } \pm \text { S.D. } \\
(\mathrm{n}=30)\end{array}$ \\
\hline 1 & $633 \pm 46$ & $465 \pm 35$ \\
2 & $689 \pm 123$ & $517 \pm 58$ \\
3 & $552 \pm 108$ & $276 \pm 56$ \\
4 & $469 \pm 94$ & $266 \pm 56$ \\
\hline
\end{tabular}

Severe changes were present in the two animals infused with lactic acid $3.5 \mathrm{~g} \%$ and killed after 48 hours. In fig. 20, a section of bowel immediately distal to the infusion site shows distortion and shortening of the villi. The surface epithelium remained regular and columnar (fig.21).

Sections of the distal portion of the small intestine (f) from all rats studied were normal.

Normal hepatic and pancreatic structure was seen in all animals in the study (figs. 22 and 23). 


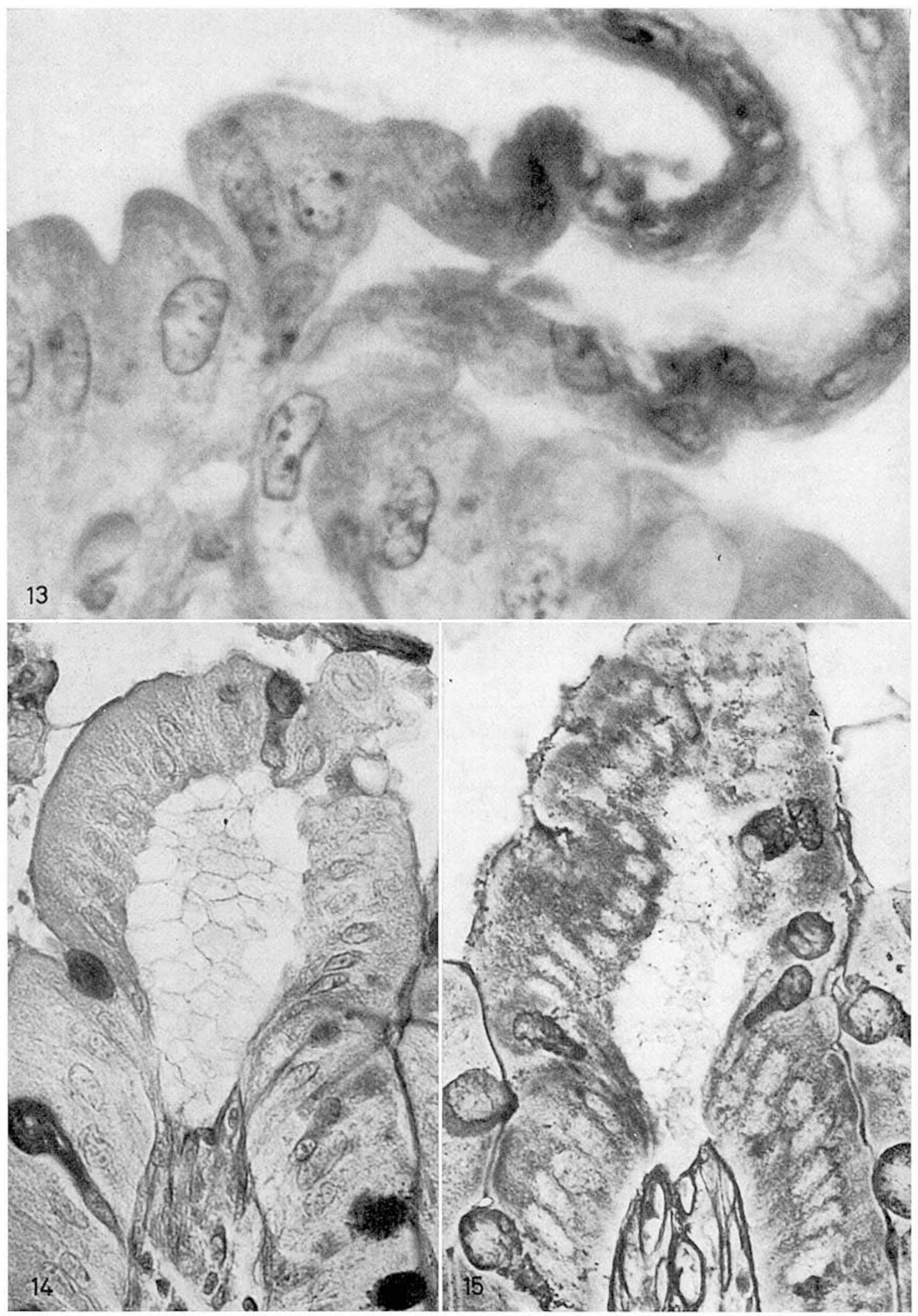



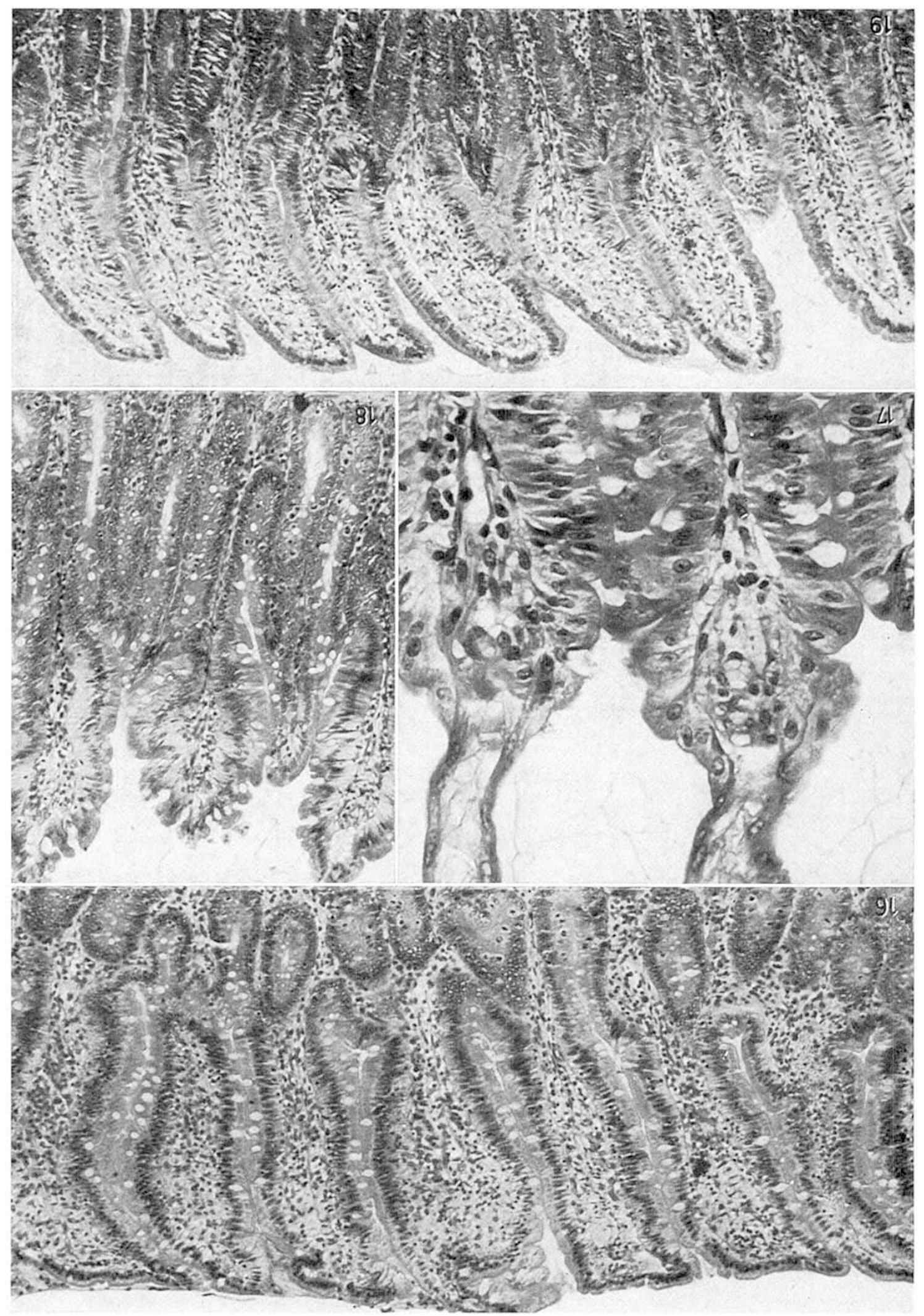


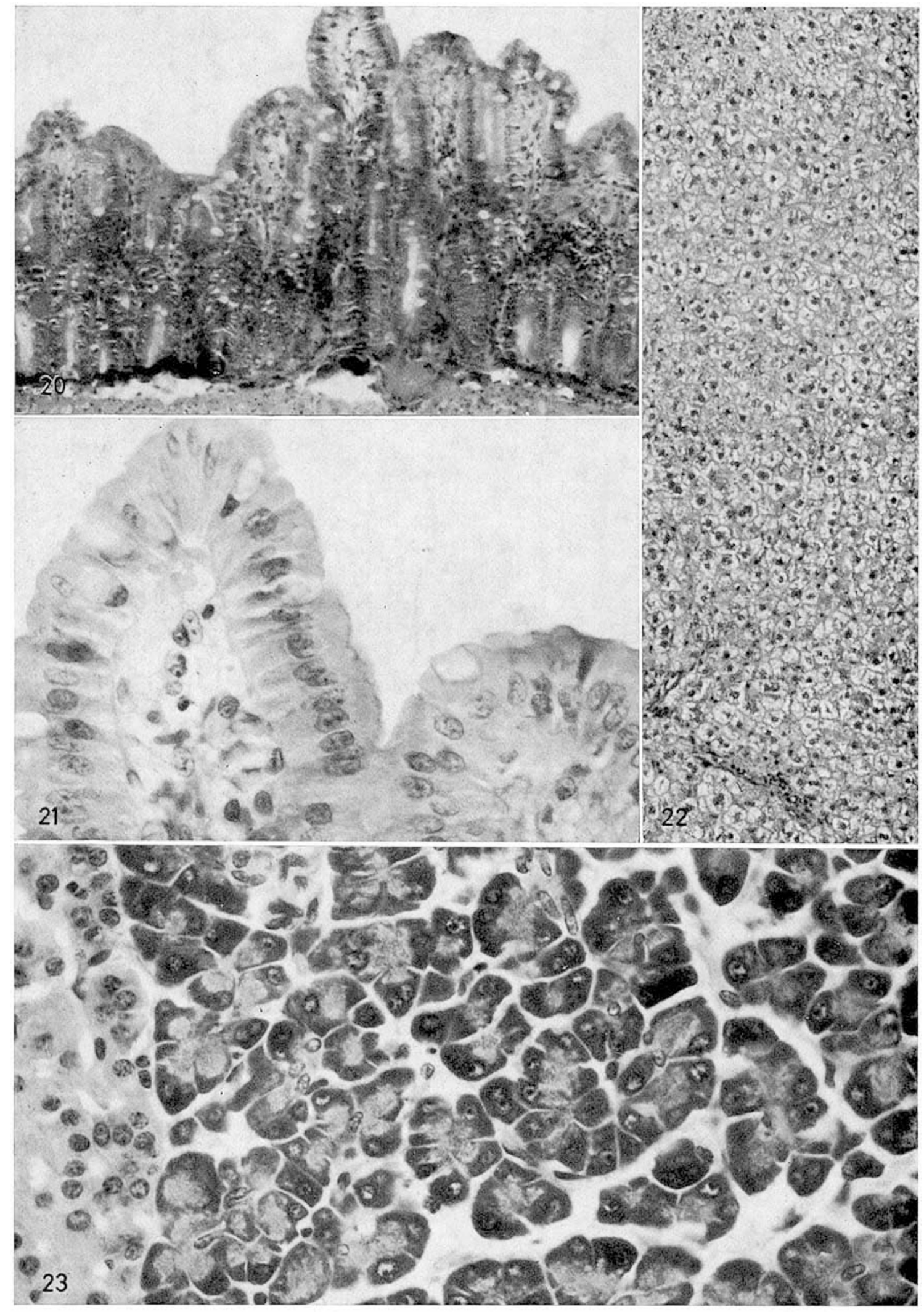


Fig. 13. Epithelial cells projecting from a villous tip forming the pedicle of a fusiform process. $\mathrm{H}$ and $\mathrm{E}$; $\times 500$.

Fig. 14. A small fusiform process showing goblet cells. PAS; $\times 200$.

Fig.15. Amorphous matrix surrounded by epithelial cells forming a small fusiform process. Reticulin; $\times 200$.

Figs. 16-19. Rat infused with lactic acid $3.0 \mathrm{~g} \%$ demonstrating more extensive changes than those seen in the group infused with $2.5 \mathrm{gm} \%$ acid.

Fig. 16. Proximal to cannula tip (a) showing minimal shortening of villi. $\mathrm{H}$ and $\mathrm{E} ; \times 30$.

Fig. 17. Level of cannula tip (c) showing fusiform projections from villous tips. $\mathrm{H}$ and $\mathrm{E} ; \times 200$.

Fig. 18. Distal to cannula tip approximately $2 \mathrm{~cm}$ (d) showing shortening of villi. $\mathrm{H}$ and $\mathrm{E} ; \times 30$.

Fig. 19. Distal to cannula tip approximately $5 \mathrm{~cm}$ (e) showing shortening of villi. $\mathrm{H}$ and $\mathrm{E} ; \times 30$.

Fig. 20. Rat infused with lactic acid $3.5 \mathrm{~g} \%$. Gross irregularity and shortening of villi at level of cannula tip (c). $\mathrm{H}$ and $\mathrm{E} ; \times 30$.

Fig. 21. Regular columnar epithelium from same tissue shown in figure $20 . \mathrm{H}$ and $\mathrm{E} ; \times 200$.

Fig.22. Normal pancreatic tissue. Rat infused with lactic acid $3.0 \mathrm{~g} \% . \mathrm{H}$ and $\mathrm{E} ; \times 200$.

Fig. 23. Normal hepatic tissue. Rat infused with lactic acid $3.0 \mathrm{~g} \%$. $\mathrm{H}$ and $\mathrm{E} ; \times 30$.

\section{Discussion}

The infusion apparatus, as described, was suitable for prolonged infusion of the upper intestinal tract in the rat. The device is simple in design and may be constructed of materials most of which are available in a hospital work shop. The transparent base simplifies maintenance of the apparatus and facilitates observation of the animals during the infusion.

Lactic acid, infused into the small bowel of the rat for a prolonged period in proper concentration, impared the normal process of fat absorption and altered mucosal structure at the infusion site. These abnormalities of both function and morphology undoubtedly were due directly to the acid infusion rather than to some secondary phenomenon such as an alteration of the enteric microflora [2]. Firstly, changes occurred rapidly after the onset of the infusion and mucosal lesions were localized rather precisely to the region of the cannula tip. Furthermore, data on dietary intake exclude malnutrition as a complicating factor except in the group infused with lactic acid $3.5 \mathrm{~g} / 100 \mathrm{ml}$. On the other hand, it cannot be concluded that the abnormalities observed were specific for lactic acid. In fact, the subsequent discussion will suggest that similar results might be anticipated if other acids were studied in the same way. It should be emphasized, however, that the particular agent used in this experiment, lactic acid, is formed in the lumen of the normal intestinal tract.

It is interesting to speculate on the possible mechanisms responsible for the defective fat absorption observed in the present study. Hofrman has postulated that excessive acidity in the duodenal lumen might depress the rate of hydrolysis of dietary triglyceride by causing fatty acid to accumulate at the water-oil interface in the bowel lumen [10]. However, the infusion was delivered to a site well beyond the level of entry of the pancreatic ducts into the duodenum. Therefore, it is unlikely that the major effect of the infused acid was on pancreatic lipolysis. In the human, Borgstrom et al. have shown that $65-70 \%$ of dietary triglyceride is hydrolyzed before it leaves the duodenum [3]. Although lesions of the absorptive cells of the intestine were observed, they were localized and cannot be implicated as primary factors in causing the steatorrhea. The explanation for the defect in fat absorption may lie in the observed disturbance of solubility of fatty acids in micellar solutions leading to impaired micellar formation at low $\mathrm{pH}[11]$. Impairment of micellar formation would lead to defective fat absorption since it is in the form of micelles that most dietary fats are absorbed [19].

The clinical situation in which hyperacidity of the proximal intestine is most frequently recognized is the 
Zollinger-Ellison syndrome [29]. In these patients, steatorrhea may develop secondary to the passage of excessive hydrochloric acid into the small intestine [18, 22]. The relevance of these clinical observations to the present discussion is difficult to assess. In such cases, excessive acidity occurs in the duodenum where its potential to influence pancreatic lipolysis is greater than that of acid instilled into the jejunum.

Morphological abnormalities similar to those described in the present study have been produced in isolated segments of intestine of the experimental animal by a number of irritant agents, including acids. WILLIAMs isolated segments of rat intestine at laparotomy and assessed the effect on mucosal structure of various solutions placed in the loop for a two-minute period [26]. Hydrochloric acid $(0.2 \mathrm{~N})$ and formic acid $(0.1 \%)$ produced ulcers that on healing were replaced by shortened villi. As in the present experiment, the effect depended on the concentration of the acid used. More concentrated solutions caused necrosis of the entire thickness of the bowel wall. TownLEy et al. isolated dog jejunum and repeatedly instilled $\mathrm{NHCl}$ into the bowel lumen over a ten-week period. Flattening of the villous structure was noted; it returned to normal after cessation of the acid instillations [23]. In addition to the presence of islands of gastric epithelium in the duodenum of patients with the Zollinger-Ellison syndrome, JAMEs found shortened villi [13]. Additional observations of villous atrophy of the jejunal mucosa in such patients have been recorded $[6,21]$ although in most cases in which intestinal biopsies have been studied, the mucosa has been normal [21].

It has been suggested that the shape of villi is dependent upon the rate of turnover of their epithelial cells $[5,6]$. In the normal rat, the mucosal epithelial cell moves from the crypt to the tip of the villus from which it is subsequently shed into the bowel lumen [15]. In the present experiment, it is more probable that the fusiform processes of epithelial cells were extrusions from the villi rather than the result of constriction of the villous shafts since there were no cellular elements within their cores. Also, the finding of a narrow pedicle extending from the very tip of the villus was consistent. These extrusions probably indicate a derangement of epithelial cell turnover although it cannot be stated whether the rate of replacement of those cells was increased or decreased. EDER studied epithelial cell turnover in rat intestinal mucosa after ulcerating damage with $0.5 \mathrm{NHCl}$ in $10 \%$ hydrogen peroxide [8]. His results suggested an increased rate of cell migration from the crypts as studied by $\mathrm{H} 3$ thymidine.

The results of the present experiment may be perplexing to the pediatrician since in children with congenital intolerance to dietary disaccharide excessive amounts of lactic acid are produced in the intestinal tract, yet with rare exceptions $[14,16,25]$ these patients have neither steatorrhea nor mucosal lesions [20]. In such cases, it is probable that the acid is produced distal to the site where fat is absorbed and distal to the point at which tissue is taken for biopsy.

\section{Summary}

A technique for the continual prolonged infusion of solutions into the proximal intestine of the intact rat was described. The infusion of lactic acid in a concentration of $2.5 \mathrm{~g} \%$ or $3.0 \mathrm{~g} \%$ for 10 days produced increased excretion of fat in the feces and localized lesions of the intestinal mucosa. The lesions were characterized by shortened villi and, in some rats, abnormalities of the surface epithelium.

\section{References and Notes}

1. Barnes, R.H.; Fiala, G. and Kwong, E.: Decreased growth rate resulting from prevention of coprophagy. Fed. Proc. 22: 125 (1963).

2. Bohnhoff, M.; Miller, C.P. and Martin, W.R.: Resistance of the mouse's intestinal tract to experimental salmonella infection. II. Factors responsible for its loss following streptomycin treatment. J. exp. Med. 120: 817 (1964).

3. Borgstrom, B.; Dahlqvist, A.; Lundh, G. and SJovall, J.: Studies of intestinal digestion and absorption in the human. J.clin. Invest. 36: 1521 (1957).

4. Brown, H. O.; Levine, M. L. and Lipkin, M.: Inhibition of intestinal epithelial cell renewal and migration induced by starvation. Amer. J. Physiol. 205: 868 (1963).

5. Creamer, B.: Variations of small intestinal villous shape and mucosal dynamics. Brit. med.J. ii: 1371 (1964).

6. Creamer, B.: Small intestinal mucosal dynamics and the environment. Brit.med.J. ii: 1373 (1964).

7. Dreyfus, L.: De l'intoxication rectale par les acides. G. R. Soc. Biol. (Paris) 83: 136 (1920).

8. EDER, M.: Experimentelle Untersuchungen über Schädigungen der Darmschleimhaut. Verh.dtsch. Ges. Path. 49: 330 (1965).

9. Foot, N. C. and Menard, M. C.A.: Rapid method for the silver impregnation of reticulum. Arch. Path. Lab. Med. 4: 211 (1927).

10. Hofmann, A.F.: A physicochemical approach to the intraluminal phase of fat absorption. Gastroenterology 50: 56 (1966).

11. Hofmann, A.F.: The function of bile salts in fat absorption. Thesis, University of Lund, Sweden (1964). 
12. Holtzman, J.L. and ViseK, W.J.: An apparatus for continuous gastric infusion of small animals. J. Lab. clin. Med. 63: 894 (1964).

13. James, A.H.: Gastric epithelium in the duodenum. Gut 5: 285 (1964).

14. Kern, F., Jr.; Struthers, J. E., Jr. and Attwood, W.L.: Lactose intolerance as a cause of steatorrhea in an adult. Gastroenterology 45: 477 (1963).

15. Leblond, C.P. and Stevens, C. E.: Constant renewal of intestinal epithelium in albino rat. Anat. Rec. 100: 357 (1948).

16. Lifshitz, F. and Holman, G.H.: Disacchardase deficiencies with steatorrhea. J.Pediat. 64: 34 (1964).

17. Metchnikoff, E.: The nature of man-studies in optimistic philosophy (ed. Mrtckell, G.P.) (Putmans and Sons, New York 1908).

18. Rawson, A.B.; England, M.T.; Gillam, G.G. and French, J.M.: Zollinger-Ellison syndrome with diarrhea and malabsorption. Lancet $i: 131$ (1960).

19. SENIOR, J.R.: Intestinal absorption of fats. J. Lipid Res. 5: 495 (1964).

20. Rey, J. et Fiezal, J. : Les anomalies des disaccharidases. Arch. franç. Pédiat. 24: 65 (1967).

21. Singleton, J.W.; KeRn, F., Jr. and Waddell, W.R.: Diarrhea and pancreatic islet cell tumor. Gastroenterology 49: 197 (1965).

22. Summerskill, W.J.: Malabsorption and jejunal ulceration due to gastric hypersecretion with pancreatic islet cell hyperplasia. Lancet $i: 120$ (1959).

23. Townely, R.R.W.; CAss, M.H. and Anderson, C. M.: Small intestinal mucosal patterns of coeliac disease and idiopathic steatorrhoea seen in other situations. Gut 5: 51 (1964).
24. Van de Kamer, J.H.; Ten Bokkel Huinink, H. and Weijers, H.A.: Rapid method for the determination of fat in feces. J.biol. Chem. 177: 347 (1949).

25. Weijers, H.A.; Van de Kamer, J.H. ; Dicke, W.K. and IJsseling, J.: Diarrhea caused by a deficiency of sugar splitting enzymes I. Acta Pediat. 50: 55 (1961).

26. Williams, A.W.: Experimental production of altered jejunal mucosa. J. Path. Bact. 85: 467 (1963).

27. Wilson, T.H.: Intestinal absorption (Saunders, Philadelphia 1962).

28. Young, E. G. and Smith, R. P.: Lactic acid: A corrosive poison. J.amer.med.Ass. 125: 1179 (1944).

29. Zollinger, R.M. and Ellrson, E.H.: Primary peptic ulcerations of the jejunum associated with islet cell tumors of the pancreas. Ann. Surg. 142: 709 (1955).

30. I am most grateful to Dr. W.Vrsek for his assistance in the design of the infusion technique described. The apparatus was modified and built by Mr. E.J. Wainman, Prosthetics Department, Hospital for Sick Ghildren. I am indebted to Dr. W.S. HARTROFT and Dr. J.M. FrENCH, Birmingham, England, for helpful suggestions and to Mr. WILLIAM WILSON for the histological preparations.

31. Supported by a grant from the Medical Research Council of Canada.

32. Presented in part at the meeting of the Society for Pediatric Research, Atlantic City, April, 1967.

33. Hamilton, J.R., M.D., The Hospital for Sick Children, 555 University Avenue, Toronto 2, Ontario (Canada). CIBA Medical Research Fellow, 1965-1966. 